\title{
Preschool Literacy and the Common Core: A Professional Development Model
}

\author{
Donna G. Wake ${ }^{1}$ \& Tammy Rachelle Benson ${ }^{1}$ \\ ${ }^{1}$ Department of Teaching and Learning, University of Central Arkansas, Conway, Arkansas, USA \\ Correspondence: Tammy Rachelle Benson, Department of Teaching and Learning, University of Central \\ Arkansas, 201 Donaghey, Conway, Arkansas, 72035, USA. E-mail: tammyb@uca.edu
}

Received: May 16, 2016

Accepted: June 3, 2016

Online Published: June 27, 2016

doi:10.5539/jel.v5n3p236

URL: http://dx.doi.org/10.5539/jel.v5n3p236

\begin{abstract}
Many states have adopted the Common Core Standards for literacy and math and have begun enacting these standards in school curriculum. In states where these standards have been adopted, professional educators working in K-12 contexts have been working to create transition plans from existing state-based standards to the Common Core standards. A part of this process has included re-aligning professional development models to support implementation of these new standards. While K-12 professional educators have been hard at work in this changeover, little attention has been paid to early childhood contexts and the need of pre-school curriculum to support learners in moving toward new kindergarten goals in the Common Core.

This study examines the alignment between an existent professional development model for preschool literacy widely employed in one Southern state and the new Common Core Standards. The researcher's goal was to examine the existent professional development model to determine if the offered curriculum supported teachers in supporting learners' knowledge and skills expected in a kindergarten classroom preparing students for the common core. The researchers sought to determine where the curriculum supported learners in this new standards environment as well as to recommend revising the professional development content as necessary in light of the new standards. The overarching goal of the study was to support preschool teachers' abilities to prepare their students for the new expectations for school-based literacy.
\end{abstract}

Keywords: emergent literacy, preschool literacy development, professional development

\section{Introduction}

The Common Core Standards reflect a change in the state's curriculum to focus more on relevancy and real-world applications of literacy and less on discrete skills-based instruction. While skills to prepare learners for college and career are considered important, the Common Core model reflects the idea that these skills should be embedded in authentic literacy contexts and practices. Additionally, the standards provide a new national curriculum and circumvent the various and widely diverse state-controlled curricula that preceded this model.

Of concern to the researchers of this study was the alignment of the new Common Core State Standards with existing preschool literacy professional development practices. Currently the state where this study occurred has a well-developed and robust preschool literacy curriculum and assessment model; however, the researchers questioned how well that curriculum would now prepare young learners to enter classrooms now implementing the new Common Core standards. Both researchers are licensed educators with experience in early childhood classrooms and with extensive backgrounds in early childhood literacy development. Both researchers are teacher educators currently working in a university program preparing early childhood and elementary teachers and are licensed to provide the state-approved preschool literacy program examined in this study. The concerns shared by the researchers led them to develop the following research questions for the purposes of this study:

- What is the impact of an implemented curriculum on participants' perceptions of their ability to prepare young learners to meet the new Common Core literacy standards?

- How does the existent professional development model align with the newly adopted Common Core literacy standards? 
- What are curriculum implications that may indicate revisions to the current professional development model to better prepare preschool children for entrance to kindergarten?

\subsection{Developmental Literacy Needs for Preschool Learners}

Today's preschool teachers feel pressure to ensure that young children go to school prepared to learn and to be successful. The overwhelming negative life consequences of students who are not successful in school-based reading and writing contexts are remarkable. Success in school literacy contexts hinges on a solid early foundation (Tompkins, p. 23). Preschool literacy standards in oral language and literacy are building blocks supporting students' ability to be successful, and that success is elevated if children already have strong backgrounds in this area prior to that first day of kindergarten.

Knowing how children learn to read and write is critical for preschool teachers. Vukelick and Christie (2009) encourages a blended early literacy instruction approach which includes both major theoretical perspectives on reading and writing: emergent literacy and scientifically based reading research. Machado (1999) stresses the importance of a process approach to teaching skills such as rudimentary writing processes, concepts about print, and literature and the sense of story in her book Early Childhood Experiences in Language Arts, which was used as a "textbook" for the professional development training in this study.

The National Association for the Education of Young Children (NAEYC) and the International Reading Association (IRA) have joined forces to share principles and recommendations for teaching practice and public policy that emphasize birth to age eight as the most important period of literacy development (Neuman, Copple, $\&$ Bredekamp, 2000). These principles are aligned closely with the topics of professional development offered in our study to include skills such as understanding and using vocabulary, developing sensitivity to sounds and their ability to make words, naming letters and sounds associated with those letters, and the overall emerging knowledge about print (Landry, Swank, Smith, Assel, \& Gunnewig, 2006).

\section{Professional Development}

Preschool teachers who are provided with high-quality professional development tend to have more students who are prepared for learning by the time they reach kindergarten (Beauchat, Blamey, \& Walpole, 2009). The Association for Supervision and Curriculum Development note characteristics of effective professional development include a direct focus on (a) helping students reach their learning goals, (b) a collaborative effort with other teachers and providers of services to students, and (c) a school-based, long term commitment to student growth differentiated by student needs and tied to the school's goals (Zimmerman \& May, 2003). Desimone (2011) found that successful professional development opportunities included (a) a content focus, (b) active learning and participation opportunities, (c) an emphasis on collaborative and team building activities, (d) coherence with other professional development experiences, and (e) content delivered over time to include at least 20 hours of contact time. When professional development meets the above expectations, there is more likely to be a positive impact on children and their learning, as well as teachers and their job satisfaction (Wasik, 2010).

While the curriculum featured in this article meets these criteria for effective professional development, it may fall short of having enough contact hours to ensure long-term instructional change. In the state where this study occurred, preschool teachers are required to attend 30 hours of professional development per year to include 4 hours in technology and 2 hours on working with parents. The curriculum underpinning this study includes and meets the 30 hour minimum requirement. This is more than the 20 hours necessary for impact cited in Desimone's 2011 study. Unfortunately, other professional development studies indicate that for real instructional change to take place, a minimum of 49 hours of professional development is required (Yoon, Duncan, Lee, Scarloss, \& Shapley, 2007; Sawchuk, 2010). This should be considered a possible limitation of the study.

\section{Existent Curriculum}

Preschool teachers are an integral component in promoting literacy in early childhood classrooms. Each day they have opportunities to engage children in meaningful language and literacy experiences. For the past 10 years, the state where this study took place has been involved in a state-endorsed professional development training that advances teacher knowledge of how three to five year old children develop language and literary skills and why it is important that children develop these skills. This training focuses on tools and techniques teachers can use on a daily basis to help children develop language and literacy skills they will need to become proficient readers and writers. This training has the sole purpose of assisting teachers in developing strategies for promoting language and literacy experiences of young children at school and at home to include strategies for involving families in their learners' language and literacy experiences. 
The literacy curriculum for this professional development model includes thirty hours of instruction focused around the state's Early Childhood Education Framework Handbook. Depending on the location where the development is offered, the five days may be offered consecutively or spread across several weeks' time depending on the trainers' schedules. All trainers for the curriculum have attended a similar 30 hour "train-the-trainer" workshop prior to presenting the curriculum to preschool teachers. Participants receive a participant manual, the printed early childhood frameworks for the state, a classroom text set of children's books, a certificate of completion, and continuing education units.

The 30 hours of training includes 16 topics as follows: (1) The Foundation for Language and Literacy Learning, (2) Creating Learning Environments That Are Literacy Rich, (3) Supportive Social and Emotional Environments, (4) The Role of Play in Promoting Language and Literacy, (5) Fostering Children's Emergent Literacy Development Through the Family, (6) Assessment Through Observation and Portfolios, (7) Language Development, (8) Phonological Awareness, (9) Mother Goose Rhymes, Fingerplays, Poetry and Songs, (10) Storytelling, (11) Dramatic Play and Creative Drama, (12) Read Aloud, (13) Shared Reading, (14) Learning About Letters, Sounds and Words, (15) Environmental Print, and (16) Writing in the Preschool Classroom. Topics are scheduled according to depth and breadth of content covered; some are scheduled for one hour of presentation while others receive up to three hours.

All topics are designed to provide preschool teachers with support in meeting the state's Early Childhood Education Framework for Three and Four Year Old Children (2004). This document is a set of standards for preschool learners designed to "shape and guide the design and development of quality early childhood education programs" (p. 1). Specifically, the standards used for this professional development come from Strand Three: Cognitive/Intellectual Learning and Strand Five: Language. The curriculum provided to the trainers aligns the topics presented to specific frameworks (Table 1).

Table 1. Early childhood education framework for three and four year old children: language strands

\begin{tabular}{|c|c|c|}
\hline $\begin{array}{l}\text { Early Childhood Education } \\
\text { Framework }\end{array}$ & $\begin{array}{l}\text { Professional Development } \\
\text { Curriculum Topics }\end{array}$ & $\begin{array}{l}\text { Common Core Standards for } \\
\text { Kindergarten Literacy }\end{array}$ \\
\hline $\begin{array}{l}\text { 3.1 Shows enjoyment of books and } \\
\text { stories and discussion of them }\end{array}$ & $\begin{array}{ll}\bullet & 12 \text { Read Aloud } \\
\bullet & 13 \text { Shared Reading }\end{array}$ & $\begin{array}{l}\text { - Reading: Literature } \\
\text { - Reading: Informational } \\
\text { Texts }\end{array}$ \\
\hline $\begin{array}{l}3.2 \text { Tells a story in sequence, } \\
\text { following the pictures in a book }\end{array}$ & $\begin{array}{l}-\quad 10 \text { Storytelling } \\
\text { - } \quad 13 \text { Shared Reading }\end{array}$ & $\begin{array}{l}\text { - Reading: Literature } \\
\text { - Reading: Informational } \\
\text { Texts }\end{array}$ \\
\hline $\begin{array}{l}\text { 3.3 Demonstrates knowledge of how } \\
\text { to use a book }\end{array}$ & $\begin{array}{l}\text { - } \quad 12 \text { Read Aloud } \\
\text { - } \quad 13 \text { Shared Reading }\end{array}$ & $\begin{array}{l}\text { - Reading: Foundational } \\
\text { Skills }\end{array}$ \\
\hline $\begin{array}{l}\text { 3.4 Demonstrates visual } \\
\text { discrimination and visual memory } \\
\text { skills }\end{array}$ & $\begin{array}{l}\text { - } \quad 1 \text { Foundation of } \\
\text { Language and Literacy }\end{array}$ & $\begin{array}{l}\text { - Reading: Foundational } \\
\text { Skills } \\
\text { - Language }\end{array}$ \\
\hline $\begin{array}{l}3.5 \text { Understands that print conveys a } \\
\text { message }\end{array}$ & $\begin{array}{l}\text { - } \quad 9 \text { Mother Goose Rhymes, } \\
\text { Fingerplays, Poetry, and Songs } \\
\text { - } \quad 12 \text { Read Alouds } \\
\text { - } \quad 13 \text { Shared Reading }\end{array}$ & $\begin{array}{l}\text { - Reading: Foundational } \\
\text { Skills }\end{array}$ \\
\hline $\begin{array}{l}\text { 3.6 Demonstrates an interest in } \\
\text { using writing for a purpose }\end{array}$ & $\begin{array}{l}-16 \text { Writing in the } \\
\text { Preschool Classroom }\end{array}$ & - Writing \\
\hline $\begin{array}{l}\text { 3.7 Identified letters and signs in the } \\
\text { environment }\end{array}$ & $\begin{array}{l}\text { - } \quad \text { 14 Learning About } \\
\text { Letters, Sounds, and Words } \\
\text { - } \quad 15 \text { Environmental Print }\end{array}$ & $\begin{array}{l}\text { - Reading: Foundational } \\
\text { Skills }\end{array}$ \\
\hline $\begin{array}{l}3.8 \text { Uses known letters or } \\
\text { approximation of letters to represent } \\
\text { written language }\end{array}$ & $\begin{array}{l}-16 \text { Writing in Preschool } \\
\text { Classroom }\end{array}$ & $\begin{array}{l}\text { - Reading: Foundational } \\
\text { Skills } \\
\text { - Writing }\end{array}$ \\
\hline 3.9 Identifies some letters and & 8 Phonological & - Reading: Foundational \\
\hline
\end{tabular}


makes some letter-sound matches

5.1 Demonstrates phonological awareness (hearing and recognizing the sounds of language)

\subsection{Uses effective oral}

communication skills: speaking in complete sentences, speaking with appropriate grammar

5.3 Expands vocabulary

5.4 Recognizes and identifies by name most common objects and pictures

5.5 Participates in songs, Finger plays, rhyming activities, and games

5.6 Uses words to communicate ideas and feelings

\subsection{Engages in two way} conversation with children and adults

5.8 Participates in group discussion

5.9 Uses language to problem solve

5.10 Follows directions in sequence
Awareness

- 7 Language Awareness

- 14 Learning About

Letters, Sounds, and Words

- 8 Phonological

Awareness

- 14 Learning About

Letters, Sounds, and Words

- 10 Storytelling

- 7 Language Development

- $\quad 15$ Environmental Print

- 2 Creating Learning

Environments that are Literacy

Rich

- 4 The Role of Play in Promoting Language and Literacy

- 7 Language Development

- 9 Mother Goose Rhymes, Fingerplays, Poetry, and Song

- 11 Dramatic Play and Creative Drama

- 3 Supportive Social and Emotional Environments

- $\quad 4$ The Role of Play in Promoting Language and Literacy

- 3 Supportive Social and Emotional Environments

- 4 The Role of Play in

Promoting Language and Literacy

- 5 Fostering Children's

Emergent Literacy

Development Through the Family

- 7 Language Development

- 4 The Role of Play in

Promoting Language and

Literacy

- 7 Language Development

- 4 The Role of Play in

Promoting Language and

Literacy
Skills

- Writing

- Language

- Reading: Foundational Skills

- Language

- Speaking and Listening

- Language

- Language

- $\quad$ Speaking and Listening

- $\quad$ Speaking and Listening

- $\quad$ Speaking and Listening

- $\quad$ Speaking and Listening

- Speaking and Listening

- $\quad$ Speaking and Listening

- $\quad$ Speaking and Listening

- 7 Language Development 
The language arts subset of Strand Three includes nine standards (Table 1). The focus of these nine standards is on the skills needed for reading and writing. Frameworks involve teachers and learners in reading and discussing a wide range of books; concepts about books; concepts about print; visual discrimination skills; alphabetic knowledge; modeled and shared writing; and basic phonics (letter-sound matches).

Strand Five specifically focuses on language development and includes ten standards (Table 1). The focus of these standards is on the development of speaking and listening skills. Frameworks involve teachers and learners in attending to sounds of language (phonological awareness); speaking in complete sentences with appropriate grammar; expanding oral vocabulary; environmental print; songs, finger plays and rhyming activities; using language for expressing feelings and ideas; conversations and discussion; asking and answering questions; retelling; and following directions.

\section{Common Core Standards}

The Common Core Standards were written by the National Governors Association (NGA) and the Council of Chief State School Officers (CCSSO) and reflect the next stage of accountability for educators and schools with the goal of preparing students to compete in a global economy (About Achieve, 2011). The literacy and mathematics standards were released in 2010 and have been adopted by 45 of the 50 United States. This wide-spread adoption was fueled by incentive funds offered through the 2009-2010 Race to the Top initiative.

The state where this study occurred adopted the Common Core Standards as part of the Race to the Top initiative. In 2011 the state began transitioning its literacy and mathematics curricula to the new Common Core Standards with Kindergarten to $2^{\text {nd }}$ grade being the first to implement the new standards in 2011-2012 to be followed by grades 3-8 in 2012-2013 and grades 9-12 in 2013-2014. The new accountability testing system for students will be offered first in 2014 .

One of the research questions for this study was how the existent professional development model and standards aligned with the newly adopted Common Core literacy standards. An alignment chart was created by the researchers to visualize and analyze this alignment (Table 1).

Throughout the process, the two researchers worked independently as each one coded and categorized the Common Core Standards in comparison to the state early childhood language standards and the professional development curriculum. The early childhood frameworks were used as the baseline document as these frameworks were well-established and already aligned to the professional development training modules. The new element in question was the Common Core standards, and so these standards were examined through the lens of the existent frameworks in order to create the crosswalk. The two researchers then conferred to compare and contrast their findings with the goal of total agreement for each element aligned using joint-probability of agreement. Any standards not placed as expected were re-examined until consensus about placement into category was reached by the two researchers.

\section{Method}

This study used a quantitative research paradigm in seeking to understand the alignment of an existent early childhood literacy professional development model with the new Common Core standards. Specifically this examined the perceptions of participants as to their ability to prepare learners to meet the new Common Core literacy standards based on the professional development they had received. Participants were given a survey prior to and after taking part in the professional development using a pre and post format. This allowed the researchers to examine the impact of the professional development model on the participants' sense of preparedness in guiding young learners to meet the demands of the new standards. The goal of the research model was to inform the profession of the alignment of one professional development model with the new standards thus creating a model that could be generalized and replicated (Creswell, 2002).

Survey based research offers several advantages to the research design including economy of design and rapid turnaround in data collection (Creswell, 2002). This approach allows a quick assessment of participants' perceptions of the topic in a very short time frame. Survey approaches to research aim to provide quantitative description of attitudes or opinions of a sample population to the presented variable(s) by measuring the impact of a treatment (Creswell, 2002). In this case, the treatment was exposure to an ongoing professional development model for early childhood literacy and the survey was presented to the participants using a pre-/post-survey design.

The survey in this study examined how exposure to the state's preschool literacy curriculum influenced participants' perceptions of their ability to support their learners in meeting the Common Core Kindergarten standards. The Kindergarten standards were chosen as a benchmark for this study because the Common Core 
standards do not include frameworks for learners below the Kindergarten level and because preschool learners are working toward the content outlined in the Kindergarten standards. Thus the kindergarten standards seemed to the researchers to be a benchmark for preschool teachers in terms of preparing their students for entry into the public school system.

The participants were presented with a pre-/post-Likert-survey based on the Common Core Kindergarten standards. This tool did not allow for emergent input. It simply presented the Common Core Kindergarten standards and asked the participants, in the pre-survey, to rate how often they enacted the skill outlined in each standard. In the post-survey, participants were presented with the same survey, but asked to rate how often they now planned to enact the skill based on their exposure to the professional development content. This allowed the researchers to use descriptive statistics in calculating the impact of the preschool literacy curriculum presented to the participants.

\section{Participants}

Participants in the study included 38 preschool teachers enrolled in the state-provided professional development model. The preschool literacy curriculum presented in this training provided participants both with research-based content as well as with continuing education hours toward maintaining their license. Participants took part in the professional development in three groups with the first cadre taking part in fall 2011, the second cadre in spring 2012, and the final cadre in fall 2012. All participants were female. The groups represented a diverse demographic group ranging from age 25-60. Ethic groups represented were primarily European-American, with a smaller representation of African Americans and Mexican Americans.

The statistics involving the participants is aligned with research in the field which identifies early childhood teachers as female, suburban, middle class, and primarily European-American (Santoro, 2009). However, it should be noted that the participants did include a wider range of ages as well as a few more minorities than the typical teacher population. This distribution within the study demographic also fits the research base descriptive of the professional educator work force and more reflective of graduate level schooling and professional development models (Darling-Hammond, Hudson, \& Kirby, 1989).

All participants were currently employed as preschool teachers in various contexts, positions, and locations across the state. Participants worked in public preschools as well as private and public daycare facilities. There was a wide range of teaching experiences among these participants with majority having at least 10 years of experience. However, there were a small number of participants who were in their first year of teaching. Many participants were from rural areas. Participants had a range of educational backgrounds and included those without any higher education background to those who had pursued professional education degrees and licenses at the undergraduate and graduate levels.

The participants had enrolled in the professional development offered through the state department of education for reasons ranging from interest and a desire to improve in the classroom to simply a need to maintain hours toward licensure requirements. Participants had signed up for this particular professional development site through the state-maintained on-line registration system.

\section{Research Design}

This on-going study was first enacted in fall of 2011 and then repeated in spring 2012 and again in fall of 2012 with three different cohorts. The same instructors presented the state-approved curriculum in accordance with their training. The purpose of the study was explained to the participants on the first day of the training, and participants volunteered to complete the survey on their own time within the course of that first day. The survey was presented again on the last day of the training, and again participants were asked to volunteer their responses. No identifying information was collected making participation anonymous. In between the first and last day of training, participants took part in the thirty hours of professional development to include sixteen modules of curriculum. For each cohort, the training took five days dispersed across a three week span of time.

\section{Measures}

Participants completed the Emergent Literacy Practice-in-Application Survey (see Appendix) provided to them in paper format at the beginning and again at the end of their professional development training in a pre-/post-format. The pre-survey was administered in paper format during the first day of professional development, and the post-survey was administered during the final day of training, also in paper format.

The surveys were completed anonymously and no identifying information was collected. While it would have been equally efficient to provide the participants the survey via an electronic format (e.g., survey monkey), the 
researchers felt that a paper format completed during the first class session would be less threatening, more efficient, and more likely to be completed and submitted by the candidates.

The Emergent Literacy Practice-in-Application Survey was developed specifically for this study to allow the participants to self-report about the frequency they involved their learners in the activities or skills identified by the Kindergarten Common Core Standards. It was logical to the researchers that if their concern was how the literacy practices of preschool teachers aligned with the new Common Core standards, that the language from those standards should be used as the primary assessment for this study.

The Kindergarten literacy standards include six areas of literacy development with 41 discrete standards as follows:

- Reading-literature (9 standards coded RL.K.1-7, 9-10),

- Reading-informational text (10 standards coded RI.K.1-10),

- Reading-foundational skills (4 standards coded RF.K.1-4),

- writing (7 standards coded W.K.1-3, 5-8),

- speaking and listening (6 standards coded SL.K.1-6), and

- language (5 standards coded L.K.1-2, 4-6).

All of the Kindergarten standards in these six areas provided the language for the Emergent Literacy Practice-in-Application Survey. However, while the original standard read as a statement (e.g., with prompting and support, retell familiar stories, including key details), the survey posed that standard as a question with slightly different wording for the pre and post test format (e.g., how often do you have students ask and answer questions about key details in text (pre-survey) or how often will you have students ask and answer questions about key details in text (post-survey)). Participants then rated their implementation of each of these standards as always (4), often (3), rarely (2), and never (1).

\section{Results}

The data from the surveys were analyzed to determine to what degree the participants felt they were enacting each of the Kindergarten Common Core literacy standards prior to and after taking part in the preschool literacy professional development curriculum. Participants rated each standard in terms of their current (pre-) and intended future (post-) classroom use in terms of supporting student literacy development as always (4), often (3), rarely (2), and never (1). The mean was calculated for each standard (see Table 2) as well as for the six aggregated areas across the standards areas. Differences between the pre- and post-survey responses were analyzed to determine significance using a matched pairs T-test. Because not every participant completed both the pre and post survey, an $\mathrm{N}$ of 31 was the maximum achieved for data reporting.

Table 2. Pre/Post survey mean results

\begin{tabular}{ccccc}
\hline Standard & & Pre-Mean & Post-Mean & Significance \\
\hline Common Core Standard RL.K.1 & 1 & 3.065 & 3.419 & .062 \\
Common Core Standard RL.K.2 & 1 & 2.774 & 3.129 & $.046^{*}$ \\
Common Core Standard RL.K.3 & 1 & 3.097 & 3.258 & .325 \\
Common Core Standard RL.K.4 & 1 & 2.742 & 2.968 & .335 \\
Common Core Standard RL.K.5 & 1 & 2.129 & 2.677 & $.027^{*}$ \\
Common Core Standard RL.K.6 & 1 & 2.655 & 3.345 & $.021^{*}$ \\
Common Core Standard RL.K.7 & 1 & 2.419 & 2.903 & .083 \\
\hline
\end{tabular}




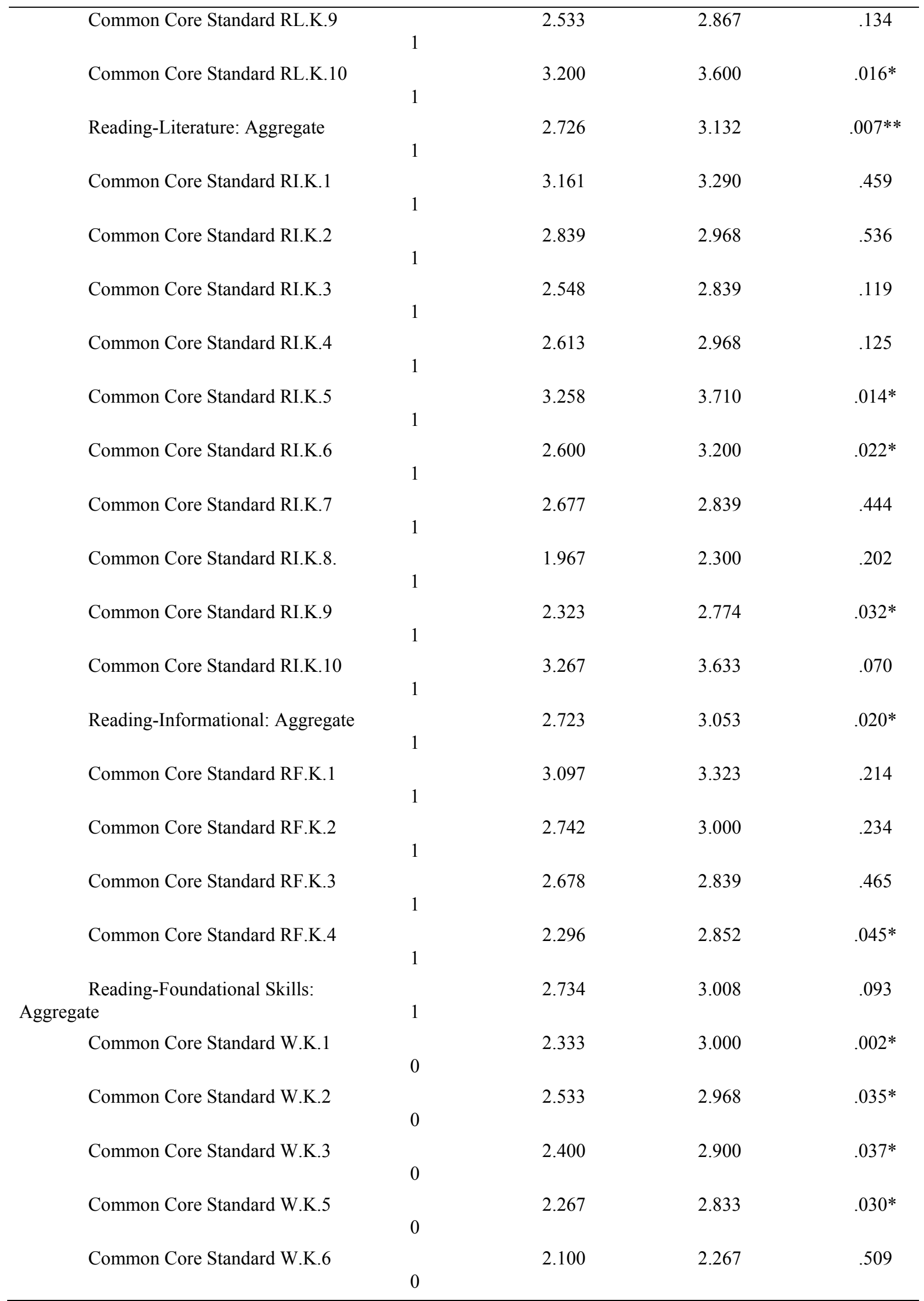




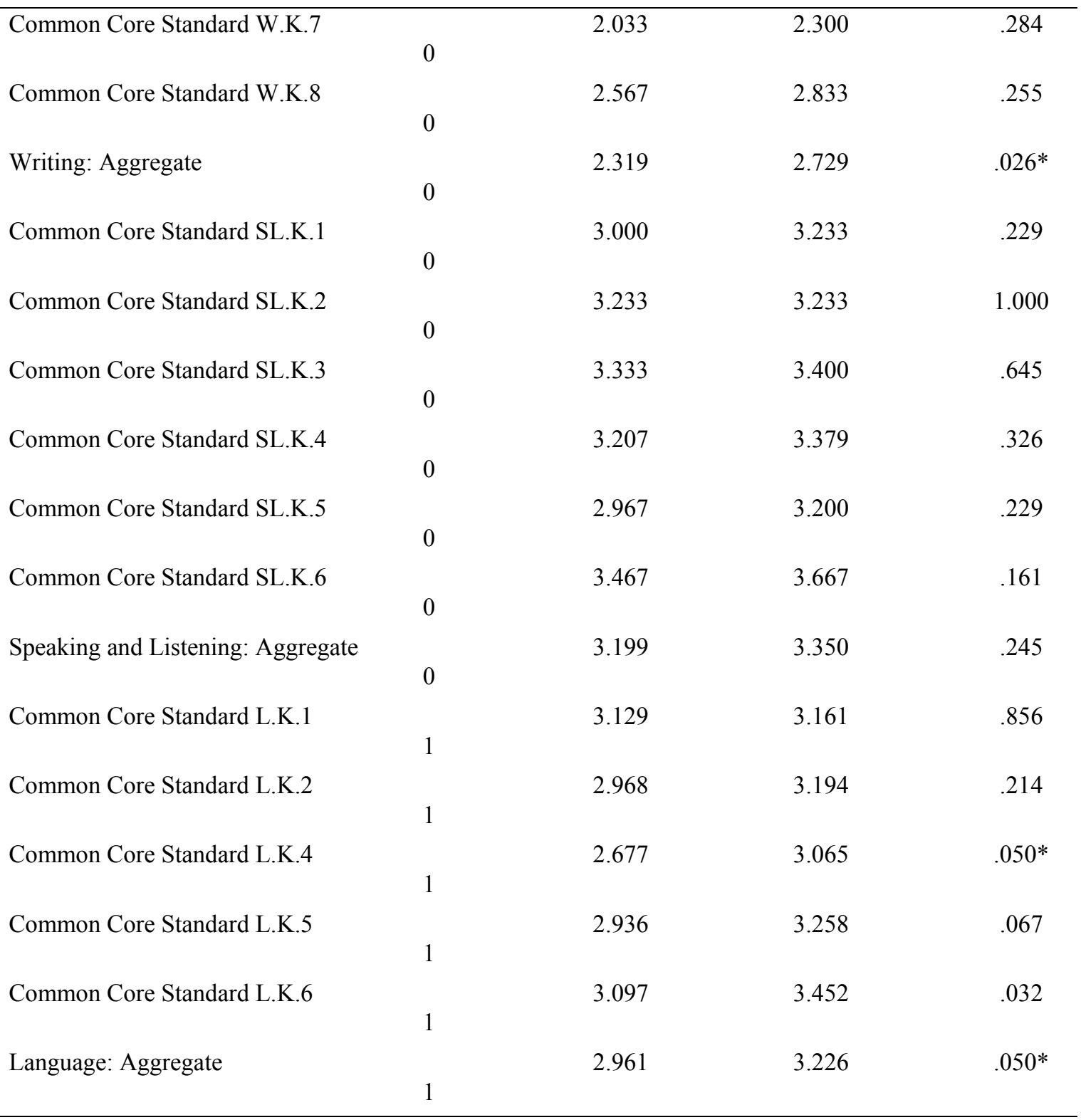

* Correlation is significant at least at the 0.05 level (2-tailed); Significance found at $\mathrm{p}<.05 ; \mathrm{p}<.01 ; \mathrm{p}<.001$.

The data yielded an interesting pattern almost immediately. While impact within the individual standards was scattered and irregular, the impact within the aggregate literacy areas was notable. Within four of the six literacy areas identified by the common core, the preschool literacy professional development curriculum appeared to have made a significant impact on participants' intentions to implement the ideas, concepts, and skills called for by the Common Core Standards. Those areas included Reading Literature $(\mathrm{p}<.01)$, Reading Informational $(\mathrm{p}<.05)$, Writing $(\mathrm{p}<.05)$, and Language $(\mathrm{p}<.05)$. The remaining two areas saw growth, but not significant growth, and included: Reading: Foundational Skills $(\mathrm{p}=.093)$ and Speaking and Listening $(\mathrm{p}=.245)$.

In addition to the significance found in these areas, the data also indicated that some areas within the survey were rated more or less strongly by the participants showing a relative positioning of skills instruction by area within the participants' presentation of curriculum. The areas showing the strongest assigned scores from the participants include Speaking and Listening (3.199/3.350) as well as Language (2.961/3.226). Both of these areas were scored highly in both the pre-survey as participants began working with the professional development curriculum and post-survey at the conclusion of the training. Conversely, Writing (2.319/2.729) was scored the lowest in both pre and post-survey results. The three reading strands-literature (2.726/3.132), informational $(2.723 / 3.053)$, and foundations $(2.734 / 3.008)$ were scored in the relative mid-range by the participants. 


\section{Discussion}

\subsection{Curriculum Effectiveness}

The primary focus of this study was on the impact an existent professional development curriculum had on preschool teachers' perceptions of their ability to support their learners in meeting the new Common Core Kindergarten literacy standards. Within each category, few individual standards met significance in examining the pre to post survey data. This indicates that the discrete standards items within each category may not be as important in instructional focus when compared to the overall construct represented by the six literacy areas outlined by the Common Core Standards. Instead, the aggregated score for each area may indicate overall performance improvement as a result of the professional development curriculum as is evidenced by the data for each literacy area. This finding speaks to viewing the literacy areas defined by the Common Core Standards as holistic, pragmatic constructs rather than a set of discrete skills or concepts.

The four areas that saw significant growth as a result of exposure to the literacy curriculum included (1) Reading Literature, (2) Reading Informational Texts, (3) Writing, and (4) Language. This indicates that the professional development model supported growth in these areas to a significant amount and that the existent curriculum was aligned with the new Common Core Standards. This finding was encouraging and meant that no significant revision to these pieces of the curriculum was necessary. The existent curriculum was clearly strong in these categories and was a good focus to maintain in the curriculum model as it supported these preschool teachers in their perceptions of ability to prepare young learners to meet the new Common Core literacy standards.

It was encouraging to find that the existent preschool literacy curriculum supported preschool teachers in reading with their learners. In disaggregating the data of the reading areas, the data indicated that the preschool teachers felt that as a result of the professional development they received, they could better support their learners in Reading Literature and Reading Informational Texts to include working with key ideas and details, paying attention to craft and structure, integrating ideas, and presenting a range of texts according to content and reading level. This was an encouraging finding. It was clear that the teachers were already reading with and to their learners; however, the data indicates that perhaps the teachers needed even further support in best practices in these areas and that the professional development model enacted did provide that support.

Participants also felt supported in their ability to provide Writing instruction. Specifically, the participants felts supported in working with learners in different text types and writing for different purposes to include drawing, dictating and drawing for opinion, information, and narrative. They also indicated that they felt better equipped to support learners in producing and distributing writing and presenting knowledge in written form. Similarly, participants felt better equipped to provide learners with instruction in Language development to include vocabulary acquisition and use as well as use of Standard English conventions (upper/lower case, noun-verb usage, plural nouns, use of questions and prepositions, and punctuation).

Interestingly, the language standards have many correlations with the writing standards to include printing upper and lower case letters, understanding capitalization and punctuation, and basic spelling. So it is logical that the areas of Writing and Language development shared similar results. However, the Language development standards also have some correlation with the Reading Foundational Skills standards in terms of Standard English usage to include awareness of basic phonics and phonemic awareness for spelling. The lack of significance in Reading Foundational Skills standard is discussed next.

Conversely, the two areas which did not see significant growth included (1) Reading Foundational Skills and (2) Speaking and Listening. This finding required further examination by the researchers. It was possible that there was a potential mismatch between curriculum and standards expectations such that the current professional development model was not perceived by the participants as supporting their work in these areas as defined by the Common Core standards. However, alternative explanations were equally viable.

The fact that these two areas were scored well or moderately well in the pre-survey data indicates a logical reason for why these two areas did not see significant growth. It may be possible that these are areas where preschool teachers feel they are already strong and may not need additional curricular support. In examining the Common Core standards for Reading-Foundational Skills, the focus clearly is on the work that preschool teachers already do routinely and heavily in their daily curriculum to include concepts about print, phonemic awareness, basic phonics awareness, and fluency. Preschool teachers also focus much of their time on the skills identified in the Speaking and Listening standards to include discussions and conversations, retelling, questioning, and oral elaborations. 
Truly, this finding was a positive one. It appears that the preschool teachers are already spending significant time on and see the value of the foundations of reading as well as on oral language skills. These are important and developmentally appropriate areas for curricular inclusion in preschool classrooms, and preschool teachers are already aware of this and are working with their learners on developing these skills ahead of the advent of the Common Core standards.

Considering that this age of child should spend more time on oral language and on the foundations of reading, the focus of preschool teachers in these categories indicates a preexistent and preferential treatment of these areas over reading literature, reading for information, writing, and language. Certainly oral language and reading foundations are areas covered in the professional development curriculum and do serve as a good refresher for participants; however, perhaps this information is already known and/or redundant to participants, and their inclusion may need some further examination and modification. Researchers should examine these areas for possible curricular revision to see if perhaps more could be done to enhance these areas of the offered curriculum to better support preschool literacy teachers or even to minimize these areas in preference for time spent in some of the areas that had weaker scores in the data set.

\subsection{Curriculum Strengths and Areas for Improvement}

While an examination of the pre- and post-test survey results yielded interesting findings, analysis of the relative strengths and weaknesses in the candidates' scoring of the Common Core curriculum areas provided additional rich and relevant data. That is, candidates scored some categories of the Common Core standards comparatively higher or lower than other areas indicating that some curriculum foci were already areas of strengths while others were areas for needed improvement in terms of their professional development needs. These relative areas of strength and areas for improvement provide additional guidance in structuring or modifying curriculum for preschool teachers' professional development in literacy.

The areas where the participants felt the strongest prior to taking part in the professional development content included Speaking and Listening and Language. Both of these areas were scored higher than the other areas in both the pre-survey and post-survey; although only Language saw a significant change. Again, if we consider the developmental needs of preschool children, then this makes sense. Preschool teachers are already spending significant time on and see the value of oral language skills. These are important and developmentally appropriate areas for curricular inclusion in preschool classrooms. The preschool teachers in this study indicated they were aware of this already and were working with their learners on developing these skills prior to attending the professional development training.

Those areas scoring in the moderate range both pre- and post-survey included Reading Literature, Reading Informational Texts, and Reading Foundational Skills. Clearly the participants were comfortable with the Reading Foundational Skills as discussed previously. These preschool teachers indicated that they already spent time teaching concepts about print, phonemic awareness, basic phonics awareness, and fluency. So while this category did not see significant change from participants taking part in the professional development model, their scoring of this category indicated a moderate level of comfort in this area and some growth as a result of the professional development they received. The two reading strands (literature, information) were also areas where these participants felt comfortable, but they also felt that exposure to the curriculum aided their ability to support learners in reading for narrative and expository purposes to a significant degree.

Finally, while significance was obtained in Writing, this area was the weakest scoring area in both the pre- and post-survey data. It may be that initially these participants did not see writing as developmentally appropriate for their learners; however, the writing instruction provided in the professional development curriculum focused on modeled, dictated, and shared writing-models of writing that allow the teacher to work as the scribe while the student composes through oral avenues. In other words, prior to taking part in this curriculum they may have viewed writing as something the child did using pen and paper. Considering that their learners are three and four year olds, this perception of writing would be difficult to support given the target learners' fine motor abilities.

Providing these participants with an alternate view of writing as composition may have opened the door to their ability to support learners in drawing and dictating and oral composition. This approach aligns with best practice recommendations for this age of learner.

While participants felt supported in the professional development curriculum in improving their instructional practice in writing as aligned to the common core standard, this was an area that was problematic before the participants took part in the curriculum and still remained an area of concern after the study concluded. This fits with research indicating that many classroom teachers are uncomfortable with writing and writing instruction 
and admit a lack of knowledge and efficacy for teaching writing (Graves, 2002; Pardo, 2006). This speaks to a need to expand the focus on writing practice and instruction with preschool learners within the existent curriculum.

\section{Limitations}

Limitations in this study include the small sample size and the fact that most of the participants worked in a rural setting. Thus the study may not be generalizable to more urban contexts. Additionally, only women were involved in this study. Future research needs to expand this study by involving more diverse participants from a wider range of educational settings.

The professional development model that is the focus of this study is only available in one state. While the model may be easily replicated, the fact of its specific geographical context may be considered a limitation. Finally, the professional development model described here only includes 30 hours whereas some research in the field recommends a minimum of 49 hours for true impact on the learner (Yoon et al., 2007; Sawchuk, 2010).

\section{Conclusion}

This study examined an existent professional development curriculum designed to support preschool teachers' literacy instruction in relation to the new Common Core Standards. The Common Core standards were found to align with the existent curriculum topics. The date findings indicate that the existent curriculum appears to have an overall positive impact on participants' perceptions of their ability to prepare their young learners to meet the new Common Core literacy standards.

The researchers conclude that the existing professional development model is supporting pre-school teachers in literacy instruction; however, some slight revisions to the current curriculum may be warranted. Participants in the study felt supported in four of the six areas for literacy development identified by the Common Core Standards. The two areas that were not supported may be areas already heavily enacted and valued by the participants prior to their exposure to the professional development model. While the curriculum may serve as a refresher for these two areas, the model may also need to be examined to possibly revise or even minimize time spent in these areas in order to provide more support in the one area the data shows as most in need of support: writing.

\section{References}

About Achieve. (2011). Achieve. Retrieved from http://www.achieve.org/about-achieve

Arkansas Department of Human Services. (2004). Arkansas Early Childhood Education Framework Handbook. Division of Child Care and Early Education.

Beauchat, K. A., Blamey, K. L., \& Walpole, S. (2009). Building preschool children's language and literacy one storybook at a time. The Reading Teacher, 63(1), 26-39. http://dx.doi.org/10.1598/RT.63.1.3

Creswell, J. W. (2002). Research design: Qualitative, quantitative, and mixed methods approaches (2nd ed.). Thousand Oaks, CA: Sage Publications.

Desimone, L. M. (2011). A primer on effective professional development. Phi Delta Kappan, 92(6), 68-71. http://dx.doi.org/10.1177/003172171109200616

Graves, D. H. (2002). Testing is not teaching: What should count in education. Portsmouth, NH: Heinemann.

Landry, S. H., Swank, P. R., Smith, K. E., Assel, M. A., \& Gunnewig, S. B. (2006). Enhancing early literacy skills for preschool children. Journal of Learning Disabilities, 39(4), $306-324$. http://dx.doi.org/10.1177/00222194060390040501

Machado, J. M. (1999). Early childhood experiences in language arts (6th ed.). Albany, NY: Delmar Publishers.

Neuman, S. B., Copple, C., \& Bredekamp, S. (2000). Learning to read and write: Ddevelopmentally appropriate practices for young children. Washington D.C.: National Association for the Education of Young Children.

Pardo, L. S. (2006). The role of context in learning to teach writing: What teacher educators need to know to support beginning urban teachers. Journal of Teacher Education, 57(4), 378-394. http://dx.doi.org/10.1177/0022487106291563

Professional Development. (2004). Education Week. Retrieved from http://www.edweek.org/ew/issues/professional-development/

Sawchuk, S. (2010). Proof lacking on success of staff development. Education Week. Retrieved from http://www.edweek.org/ew/articles/2010/11/10/11pd_research.h30.html 
Sheridan, S., \& Schuster, K. (2001). Evaluation of pedagogical quality in early childhood education: A cross-national perspective. Journal of Research in Childhood Education, 16(1), 109-125. http://dx.doi.org/10.1080/02568540109594978

Sull, T. M. (2001). Program evaluation for child care professionals. Child Care Information Exchange, 7, 75-79.

Tompkins, G. E. (2013). Literacy for the 21st century, A balanced approach (6th ed.). Boston: Pearson Education Inc.

Vukelich, C., \& Christie, J. (2009). Building a foundation for preschool literacy: Effective instruction for children's reading and writing development (2nd ed.). Newark, DE: International Reading Association.

Wasik, B. A. (2010). What teachers can do to promote preschoolers' vocabulary development: Strategies from an effective language and literacy profession development coaching model. The Reading Teacher, 63(8), 621-633. http://dx.doi.org/10.1598/RT.63.8.1

Yoon, K. S., Duncan, T., Lee, S. W., Scarloss, B., \& Shapley, K. L. (2007). Reviewing the evidence on how teacher professional development affects student achievement. Regional Educational Laboratory Southwest, Issues \& Answers Report No. 2007-033, U.S. Department of Education, Institute of Education Sciences, ERIC Document \#ED498548. Retrieved from http://ies.ed.gov/ncee/edlabs/regions/southwest/pdf/REL_2007033.pdf.

Zimmerman, J. A., \& May, J. J. (2003). Providing effective professional development: What's holding us back? American Secondary Education, 31(2), 37-48.

\section{Appendix}

Emergent Literacy Practice-in-Application Survey (Note 1)*

Reading: Literature: from the following list, please check one option $\quad$ Always $\quad$ Often $\quad$ Rarely Never (always, often, rarely, never) for each item on the questionnaire.

How often do you have students ask and answer questions about key details in text (Note 2) (RL.K.1)

How often do you ask students to retell familiar stories including key details in narrative text (RL.K.2)

How often do you ask students to identify characters, settings, and major events in a story (RL.K.3)

How often do you have students ask and answer questions about unknown words in a text (RL.K.4)

How often do you ask students to recognize common types of text (storybooks, poems, informational) (RL.K.5)

How often do you ask students to name the author and illustrator of a story and define the role of each in telling the story (RL.K.6)

How often do you ask students to describe the relationship of illustrations and the story in which they appear (e.g. what moment in a story an illustration depicts) (RL.K.7)

How often do you ask students to compare and contrast adventures and experiences of characters in familiar stories (RL.K.9)

How often do you actively engage students in group reading activities with purpose and understanding (RL.K.10)

Reading: Informational: from the following list, please check one option (always, often, rarely, never) for each item on the questionnaire.

How often do you have students ask and answer questions about key details in text (RI.K.1)

How often do you ask students to identify main topic and retell key details in informational text (RI.K.2) 
How often do you ask students to describe the connection between two events, ideas or pieces of information in a text (RI.K.3)

How often do you have students ask and answer questions about unknown words in a text (RI.K.4)

How often do you identify front cover, back cover, and title page of a book (RI.K.5)

How often do you ask students to name the author and illustrator of a story and define the role of each in presenting the ideas or information in a text (RI.K.6)

How often do you ask students to describe the relationship between illustrations and the text in which they appear (e.g. what person, place, thing, or idea in the text an illustration depicts) (RI.K.7)

How often do you ask students to identify the reasons an author gives to support points in a text (RI.K.8).

How often do you ask students to identify basic similarities and differences between two texts on the same topics (e.g., in illustrations, descriptions, or procedures) (RI.K.9)

How often do you actively engage students in group reading activities with purpose and understanding (RI.K.10)

\begin{tabular}{l}
\hline $\begin{array}{l}\text { Reading: Foundational Skills: from the following list, please check one } \\
\text { option (always, often, rarely, never) for each item on the questionnaire. }\end{array}$ \\
\hline How often do you assist students to demonstrate understanding of the \\
organization and basic features of print (Follow words from left to right, \\
top to bottom, and page by page; recognize that spoken words are \\
represented in language by specific sequences of letters; understand that \\
words are separated by spaces in print; recognize and name all upper and \\
lower case letters of the alphabet) (RF.K.1) \\
How often do you assist students to demonstrate understanding of spoken \\
words, syllables, and sounds (phonemes) (Recognize and produce \\
rhyming words; Count, pronounce, blend, and segment syllables in \\
spoken words; Blend and segment onsets and rimes of single-syllable \\
spoken words; Isolate and pronounce the initial, medial vowel, and final \\
sounds (phonemes) in three-phoneme (consonant-vowel-consonant, or \\
CVC words). (This does not include CVCs ending with /l/, /r/, or /x/.); \\
Add or substitute individual sounds (phonemes) in simple, one-syllable \\
words to make new words) (RF.K.2) \\
How often do you know and apply grade-level phonics and word analysis \\
skills in decoding words (Demonstrate basic knowledge of one-to-one \\
letter-sound correspondences by producing the primary or many of the \\
most frequent sound for each consonant; Associate the long and short \\
sounds with common spellings (graphemes) for the five major vowels; \\
Read common high-frequency words by sight (e.g., the, of, to, you, she, \\
$m y$, is, are, do, does); Distinguish between similarly spelled words by \\
identifying the sounds of the letters that differ) (RF.K.3) \\
How often do you assist students to read emergent-reader texts with \\
purpose and understanding (RF.K.4) \\
\hline
\end{tabular}


Writing: from the following list, please check one option (always, often, $\quad$ Always $\quad$ Often $\quad$ Rarely $\quad$ Never rarely, never) for each item on the questionnaire.

How often do you assist students to use a combination of drawing, dictating, and writing to compose opinion pieces in which they tell a reader the topic or the name of the book they are writing about and state an opinion or preference about the topic or book (e.g., My favorite book is ...) (W.K.1)

How often do you assist students to use a combination of drawing, dictating, and writing to compose informative/explanatory texts in which they name what they are writing about and supply some information about the topic (W.K.2)

How often do you assist students to use a combination of drawing, dictating, and writing to narrate a single event or several loosely linked events, tell about the events in the order in which they occurred, and provide a reaction to what happened (W.K.3)

How often do you assist students to respond to questions and suggestions from peers and add details to strengthen writing as needed (W.K.5)

How often do you assist students to explore a variety of digital tools to produce and publish writing, including in collaboration with peers (W.K.6)

How often do you assist students to Participate in shared research and writing projects (e.g., explore a number of books by a favorite author and express opinions about them) (W.K.7)

How often do you assist students to recall information from experiences or gather information from provided sources to answer a question (W.K.8)

Speaking and Listening: from the following list, please check one option
(always, often, rarely, never) for each item on the questionnaire.

How often do you assist students in participating in collaborative conversations with diverse partners about kindergarten topics and texts with peers and adults in small and larger groups (follow agreed-upon rules for discussions (e.g., listening to others and taking turns speaking about the topics and texts under discussion; continue a conversation through multiple exchanges) (SL.K.1)

How often do you assist students in confirming understanding of a text read aloud or information presented orally or through other media by asking and answering questions about key details and requesting clarification if something is not understood (SL.K.2)

How often do you assist students ask and answer questions to seek help, get information, or clarify something that is not understood (SL.K.3)

How often do you assist students to describe familiar people, places, things, and events and, with prompting and support, provide additional detail (SL.K.4)

How often do you assist students to Add drawings or other visual displays to descriptions as desired to provide additional detail (SL.K.5)

How often do you help students speak audibly and express thoughts, feelings, and ideas clearly (SL.K.6) 
Language Standards: from the following list, please check one option (always, often, rarely, never) for each item on the questionnaire.

Always Often Rarely Never

How often do you demonstrate command of the conventions of standard English grammar and usage when writing or speaking (e.g., - print many upper- and lowercase letters; use frequently occurring nouns and verbs; form regular plural nouns orally by adding /s/ or /es/ (e.g., dog, dogs; wish, wishes); understand and use question words (interrogatives) (e.g., who, what, where, when, why, how); use the most frequently occurring prepositions (e.g., to, from, in, out, on, off, for, of, by, with); produce and expand complete sentences in shared language activities) (L.K.1)

How often do you demonstrate command of the conventions of standard English capitalization, punctuation, and spelling when writing (e.g. (capitalize the first word in a sentence and the pronoun I; recognize and name end punctuation; write a letter or letters for most consonant and short-vowel sounds (phonemes); spell simple words phonetically, drawing on knowledge of sound-letter relationships) (L.K.2)

How often do you determine or clarify the meaning of unknown and multiple-meaning words and phrases based on reading and content. (e.g., identify new meanings for familiar words and apply them accurately (e.g., knowing duck is a bird and learning the verb to duck); use the most frequently occurring inflections and affixes (e.g., -ed, -s, re-, un-, pre-, -ful, -less) as a clue to the meaning of an unknown word) (L.K.4)

How often do you assist students to explore word relationships and nuances in word meanings (e.g., sort common objects into categories (e.g., shapes, foods) to gain a sense of the concepts the categories represent; demonstrate understanding of frequently occurring verbs and adjectives by relating them to their opposites (antonyms); identify real-life connections between words and their use (e.g., note places at school that are colorful); distinguish shades of meaning among verbs describing the same general action (e.g., walk, march, strut, prance) by acting out the meanings) (L.K.5)

How often do you assist students in using words and phrases acquired through conversations, reading and being read to, and responding to texts (L.K.6)

\section{Notes}

Note 1. Adapted from the common core standards.

Note 2. Note that in the post-survey all questions were posed as "How often will you have students....".

\section{Copyrights}

Copyright for this article is retained by the author(s), with first publication rights granted to the journal.

This is an open-access article distributed under the terms and conditions of the Creative Commons Attribution license (http://creativecommons.org/licenses/by/3.0/). 